\title{
The Effect of Two Yttria Stabilized Zirconia Powders on the Thickness of Thermal Barrier Coatings
}

\author{
Alajale Mohamed Abosdell ${ }^{1}$ and Abdulbaset Ali Frefer ${ }^{2}$ \\ ${ }^{1}$ Mechanical Engineering, Misurata University/Algaraboli, ${ }^{2}$ Mechanical Engineering, \\ Al-Fateh University/Tripoli, Libya
}

Thermal barrier coatings (TBCs) have been developed in order to increase the operating temperature in gas turbine engines components that are exposed to aggressive environments. Several applications require thicker ceramic coatings because of the increased process combustion temperatures. However, the increased thickness of TBCs increases the risk of coating failure that can lead to a reduced coating lifetime and reliability. Better understanding of the structure and deformation in these coatings is necessary for improved reliability and enhanced coating designs. The main objective of this study is to investigate the effect of using two powders with different sizes, microstructures and properties on morphology and mechanical properties.

Three thicknesses $(200,400$ and $650 \mu \mathrm{m})$ of two top coat powders Zirconia stabilized with 7wt\% yttria (YSZ) powders (ZrOY-7-10-50 and ZrOY-7) and $100 \mu \mathrm{m}$ bond coat of NiCrAlY metal powder were air plasma sprayed using $O P O-8 M$ spray machine onto Ni-base alloy sample with dimensions of $(80 \times 25 \times 2 \mathrm{~mm})$. The substrates were grit blasted to an average final surface roughness of Ra 6-10 microns and cleaned with ethyl alcohol before spraying the bond coat. The substrate was cooled on the backside during spray to introduce a required microstructure. The parameters used for plasma spray were selected to be the optimum. Characterization of the powders and coating microstructure were achieved by using optical microscope (New photo-21) and scanning electron microscope (SEM, JSM6460-LV). The coating porosity was measured using the Archimedean method and ASTM C 37388 was used as a guide for the experimental method, Microhardness was studied according to ASTM C-1326 using PMT-3 Microhardness tester. Deformation characteristics of coating carried out under static conditions using a four point bend tests.

Figure 1. ( $a$ and $b$ ) micrographs show that significant distinction in the grain shape, size and distribution of both powders, the powder ZrOY-7 has irregular grin form, while the powder ZrOY-710-50 has basically spherical shape, however a close looking in small diameter region reveals that the powder ZrOY-7-10-50 has large volumetric fraction of small particles. Figures $2 \mathrm{a}$, b revealed that both powders show more or less uniform distribution of pores, lamellae boundaries and microcracks, good adhesion of the ceramic and metallic coating at the interface can be seen, This type of microstructure was reported by other researchers ${ }^{[2,4,5]}$. With increasing thickness of a ceramic top coat layer over $400 \mu \mathrm{m}$, a higher residual stresses is expected to increase gradually ${ }^{[6]}$ which can promote longitudinal (horizontal) microcracks in the ceramic coating. This is in agreement with was reported by others ${ }^{[7]}$.

\section{Conclusions}

1- It is possible of spraying thermal barrier coatings on base of material using the air plasma (OPM-8M) machine. The obtained properties are comparable with foreign analogues.

2- Coating properties obtained from this study indicated that it is not possible to spray coatings of greater thicknesses more than $400 \mu \mathrm{m}$ under similar conditions without having many cracks and failure. 


\section{References}

1. Watson, M.S., Coating and Surface Technologies for Turbine Aerofoils, Super Alloys 2004, Warrendale, PA, USA, (TMS), (2004), 579-588.

2. Jung, S., Kim, J., Lee, J., Jung, Y., Paik, U. and Lee, K.: Microstructure and mechanical properties of zirconia-based thermal barrier coatings with starting powder morphology, Surface and Coatings Technology, 204(2009), 802-806.

3. Kucuk, A., Berndt, C.C., Senturk, U., Lima, R.S. and C. Lima, R.C., Influence of Plasma Spray Parameters on Mechanical Properties of Yttria Stabilized Zirconia Coatings, I.: Four Point Bend Test, Mater. Sci. Eng. A, 284(2000), pp. 29-40.

4. Rico, A., Garcia, G., Munez, C.J., Poza, P. and Utrilla, Mechanical Properties of Thermal Barrier Coatings After Isothermal Oxidation, Depth Sensing Indentation Analysis, Surface and Coatings Technology, (2009).

5. Wortman, D. J., Nagaraj, B. A. and Duderstadt, E.C. Thermal Barrier Coatings for Gas Turbine Use, Probability, R Mater. Sci.and Eng., A121 (1989), pp. 433-440.

6. Freborg, A., Fergusion, B., Brindley, W. and Petrus, G.: Bond Coat Considerations for Thermal Barrier Coatings, 8th Meeting of AGARD, Thermal Barrier Coatings, North Atlantic Treaty Organization, Denmark, Oct. 15-16 (1997), p. 17.

7. Choi S. R., Miller R. A. Mode I, Mode II and mixed-mode Fracture of plasma-sprayed thermal barrier coatings at ambient and elevated temperatures // NASA/TM, 2003-212185.
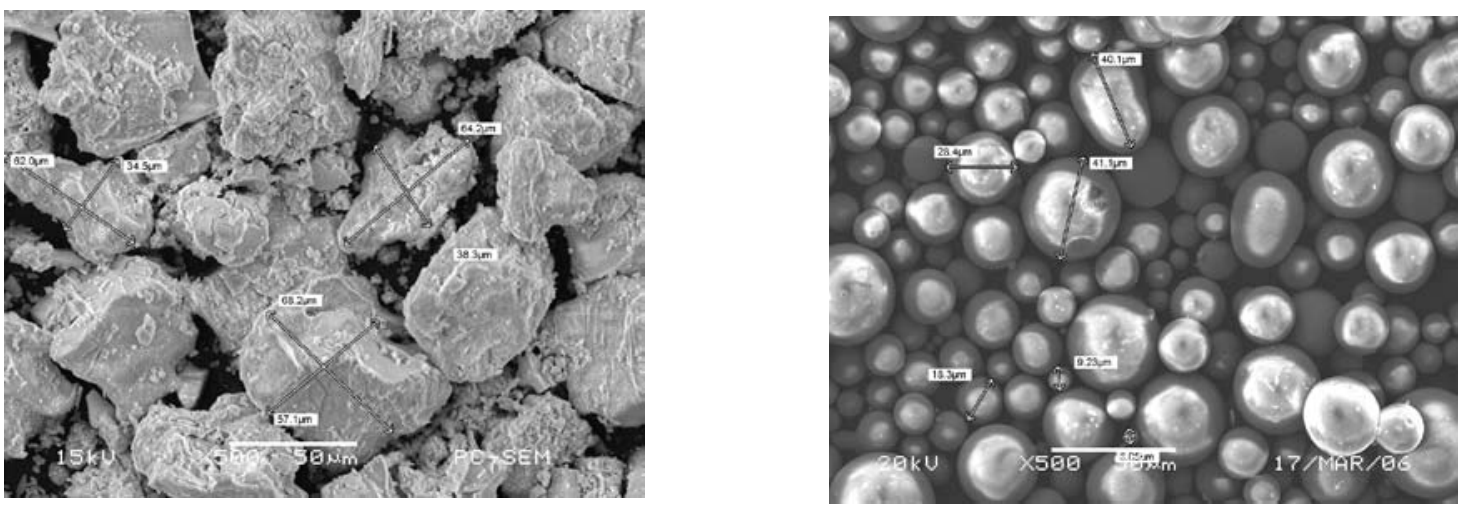

Figure. 1 (a, b) The Typical forms of particles of ceramic powder ZrOY-7 and ZrYO-710-50
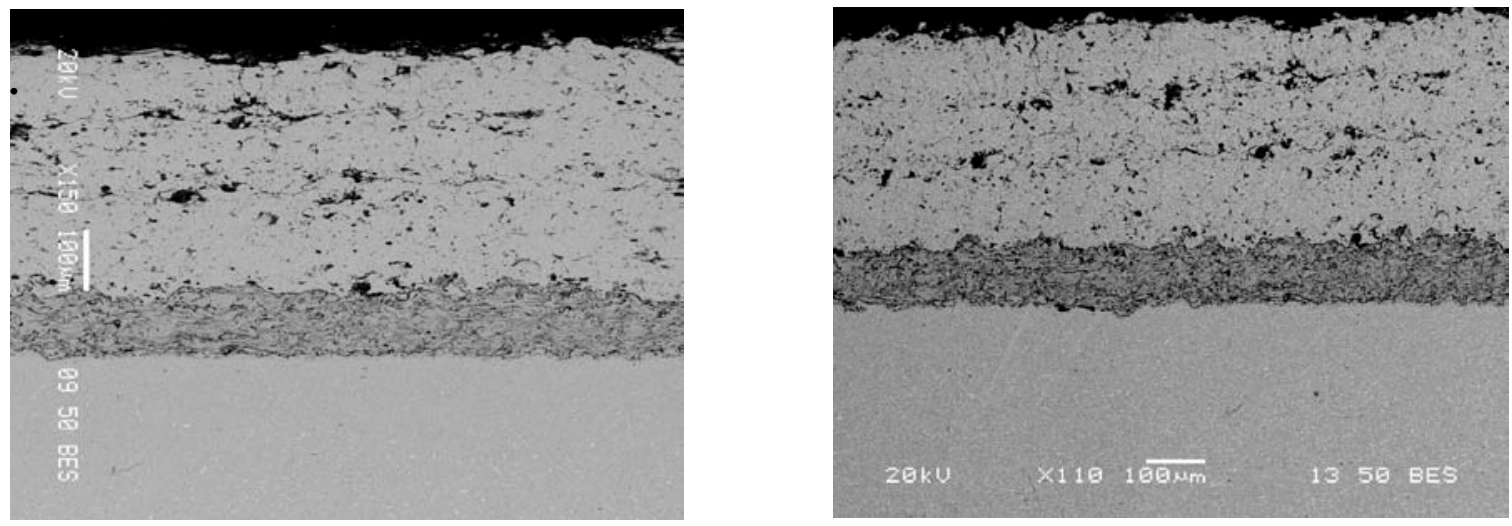

Figures. 2 (a, b) Typical microstructure of coating ZrYO-7 and ZrYO-7-10-50. 